\title{
PENINGKATAN PRODUKSI DAN DIVERSIFIKASI PRODUK DENGAN MESIN TEKNOLOGI TEPAT GUNA
}

\author{
I.K. A. Atmika ${ }^{1}$, I.G.A.K. Suriadi², I.M.D. Budiana ${ }^{3}$, I.M.G. Karohika ${ }^{4}$
}

\begin{abstract}
ABSTRAK
Industri kecil menghadapi sejumlah permasalahan terkait produksi antara lain : 1)Proses penyangraian kacang menggunakan mesin penggulingan yang relatif sederhana dengan daya tampung yang terbatas berbahan dasar plat baja serta mudah berkarat. 2)Pengemasan produk yang masih manual dengan tangan dan menggunakan lilin untuk merekatkan plastic pembungkus. 3)Pengadukan bumbu masih secara manual sehingga kurang merata. Kegiatan pengabdian dimulai dari perancangan teknis dan pembuatan alat/mesin, kemudian kegiatan di lapangan dilaksanakan untuk pengenalan/peragaan alat serta pengenalan keselamatan kerja di UD Mekar Sari dilaksanakan. Kegiatan lapangan dilaksanakan pada tanggal 04 Agustus 2018. Kegiatan diikuti oleh 15 orang peserta dari berbagai pihak antara lain anggota UD Mekar Sari, tim pelaksana pengabdian, mahasiswa Teknik Jurusan Teknik Mesin Universitas Udayana, beberapa wakil dari masyarakat setempat. Setelah pengujian dilapangan terdapat peningkatan produksi sebesar $498 \%$ atau hampir lima kali lipat. Setelah dilakukan kegiatan pengabdian dapat disimpulkan bahwa kegiatan penyuluhan tentang pentingnya teknologi tepat guna terutama yang berkaitan dengan usaha mereka serta demo dan penyerahan alat hasil rancangan mendapat respon yang baik.
\end{abstract}

Kata kunci : diversifikasi, mesin sangrai, daya tampung, pengabdian, peningkatan produksi.

\begin{abstract}
Small industries experience a number of production-related problems, including: 1) Peanut roasting using a relatively simple rolling machine with limited capacity based on steel plates and easy to rust. 2) Packaging products that are still manually by hand and using candles to glue the plastic wrap. 3) Stirring the spices manually so that they are not evenly distributed. The service activities started from the technical design and manufacture of tools / machines, then the activities in the field were carried out for the introduction / demonstration of tools and the introduction of work safety at UD Mekar Sari. The field activity was held on August 4, 2018. The activity was attended by 15 participants from various parties including members of UD Mekar Sari, the service team, Engineering students from the Mechanical Engineering Department of Udayana University, several representatives from the local community. After testing in the field there is an increase in production by $498 \%$ or almost five times. After dedication activities can be concluded that the extension activities about the importance of appropriate technology, especially those related to their efforts and the demonstration and submission of the results of the design tool received a good response.
\end{abstract}

Keyword : diversification, roasting machines, capacity, service, increased production.

\footnotetext{
${ }^{1}$ Staf Pengajar Jurusan Teknik Mesin Fakultas Teknik Universitas Udayana, tutadi2001@yahoo.com

${ }^{2}$ Staf Pengajar Jurusan Teknik Mesin Fakultas Teknik Universitas Udayana

${ }^{3}$ Staf Pengajar Jurusan Teknik Mesin Fakultas Teknik Universitas Udayana

${ }^{4}$ Staf Pengajar Jurusan Teknik Mesin Fakultas Teknik Universitas Udayana
} 


\section{PENDAHULUAN}

Sebagai sebuah industri kecil, UD Mekar Sari menghadapi sejumlah permasalahan terkait produksi antara lain : 1)Proses penyangraian kacang menggunakan mesin penggulingan yang relatif sederhana dengan daya tampung yang terbatas berbahan dasar plat baja serta mudah berkarat. 2)Pengemasan produk yang masih manual dengan tangan dan menggunakan lilin untuk merekatkan plastic pembungkus. 3)Pengadukan bumbu masih secara manual sehingga kurang merata. Permasalahan lain yang dihadapi menyangkut sumber daya manusia, manajemen dan investasi dari usaha kecil kacang curah ini. Berdasarkan tingkat pendidikan formal, rata-rata karyawan/anggota adalah kerabat dekat dan berpendidikan rendah. Industri kecil ini merupakan potret perusahaan kecil yang ada di pedesaan yang masih kental perspektif kultur dan budaya pedesaan (Mulyanto, 2006).

Kegiatan dimulai dengan merencanakan dan membuat Mesin sangrai kacang asin semi otomatis sebanyak dua buah sehingga hasil yang didapat lebih banyak dan lebih baik dibanding dengan penggunaan alat/mesin konvensional serta memberi pengetahuan cara penggunaan alat dan pengetahuan tentang keselamatan kerja dan pengendalian kualitas produk dalam kaitannya dengan penerapan Mesin sangrai kacang asin semi otomatis. Manfaat kegiatan ini adalah dengan Alat/Mesin sangrai kacang asin semi otomatis ini lebih efektif dan efisien, sehingga dapat dihasilkan kacang asin yang lebih banyak dengan kualitas yang baik dan volume pekerjaan dapat ditingkatkan 5 kali lipat dibandingkan dengan sistem konvensional dalam durasi waktu yang sama. Dengan pengeluaran biaya sedikit lebih mahal, mesin ini dapat memberikan kontribusi yang besar dari segi finansial, yang pada akhirnya akan meningkatkan pendapatan bagi para anggota kelompok usaha Bina Sejahtera maupun UD. Mekar Sari.

\section{METODE PEMECAHAN MASALAH}

Solusi atau metode pada program ini adalah mengganti peralatan penggulingan konvensional dengan mesin sangrai semiotomatis digerakkan dengan motor listrik dengan kapasitas yang lebih besar (Mott, 2009). Dalam program ini dirancang dan dibuatkan mesin sangrai kacang yang terintegrasi dengan ayakan/saringan (Mulato, 2002), yang bisa disetting kecepatannya. Mesin ini digerakkan dengan motor listrik selanjutnya ditransmisikan melalui belt-pulley serta gearbox. Mesin ini akan dirancang dengan kapasitas $20 \mathrm{~kg}$ bahan baku per jam dan bekerja secara kontinyu atau rata-rata $300 \mathrm{~kg} / \mathrm{hari}$. Pengoperasian mesin ini cukup dikerjakan oleh satu orang saja, sehingga bisa menghemat tenaga yang dari awalnya untuk proses ini dikerjakan oleh tiga orang menjadi satu orang saja, sedangkan tenaga yang tidak terpakai dapat diperbantukan dibagian pemanasan dan pengemasan.

\section{HASIL DAN PELAKSANAAN KEGIATAN}

Kegiatan pengabdian dimulai dari perancangan teknis dan pembuatan alat/mesin (Juvinall, 2007). Perhitungan dan perancangan sudah mulai dilaksanakan pada awal Mei 2018, lebih banyak dikerjakan di laboratorium komputer jurusan Teknik Mesin Universitas Udayana. Proses ini sudah selesai pada awal Juni 2018.

Berikut adalah data perencanaan alat penyangrai kacang asin antara lain :

- Kapasitas kacang yang akan disangrai $=25 \mathrm{~kg}$

- Massa komponen tabung penyangrai $= \pm 15 \mathrm{~kg}$

- Diameter tabung $=500 \mathrm{~mm}$

- Putaran poros tabung yang diperlukan $= \pm 30 \mathrm{rpm}$

- Diameter Puli 1 (motor) $=50 \mathrm{~mm}$

- Diameter Puli 2 (transfer) $=300 \mathrm{~mm}$

- Diameter Puli 3 (transfer) $=50 \mathrm{~mm}$

- Diameter Puli 4 (tabung) $=400 \mathrm{~mm}$ 
Setelah selesai perhitungan, dilanjutkan dengan perancangan teknis berupa gambar/desain global dan gambar detailnya. Desain global mesin sangrai kacang asin ditunjukkan pada gambar 1., sedangkan gambar detail ditunjukkan pada gambar 2.
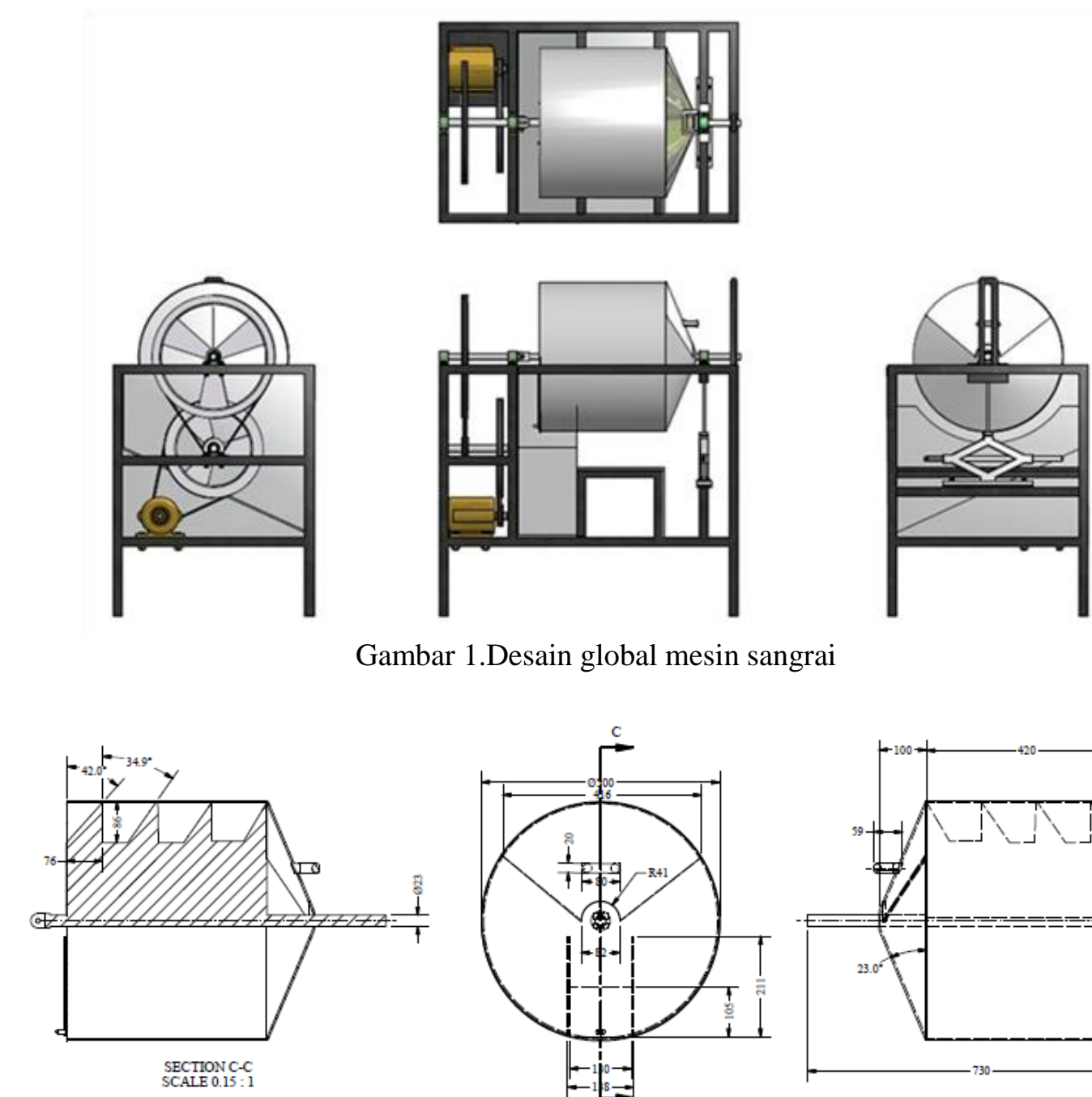

Gambar 1.Desain global mesin sangrai
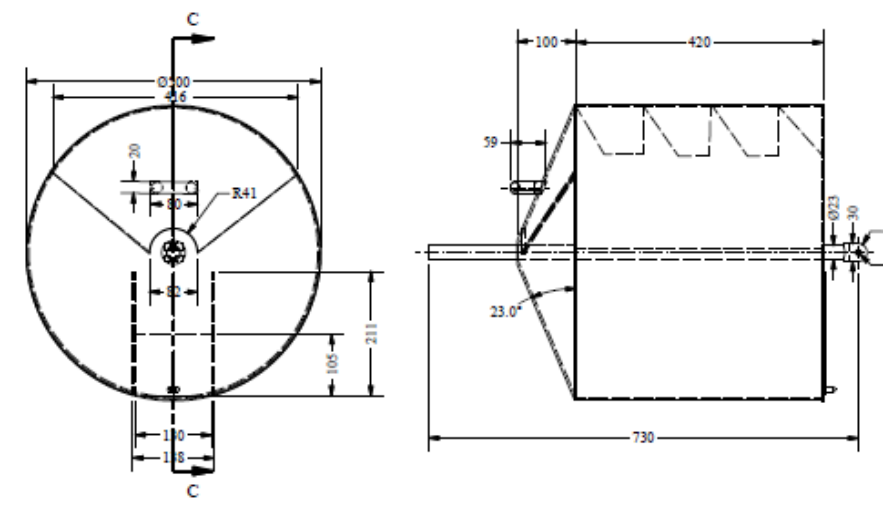

Gambar 2.Tabung sangrai kacang asin

Kegiatan lapangan dilaksanakan pada tanggal 04 Agustus 2018. Kegiatan diikuti oleh 15 orang peserta dari berbagai pihak antara lain anggota UD Mekar Sari, tim pelaksana pengabdian, mahasiswa Teknik Jurusan Teknik Mesin Universitas Udayana, beberapa wakil dari masyarakat setempat. 

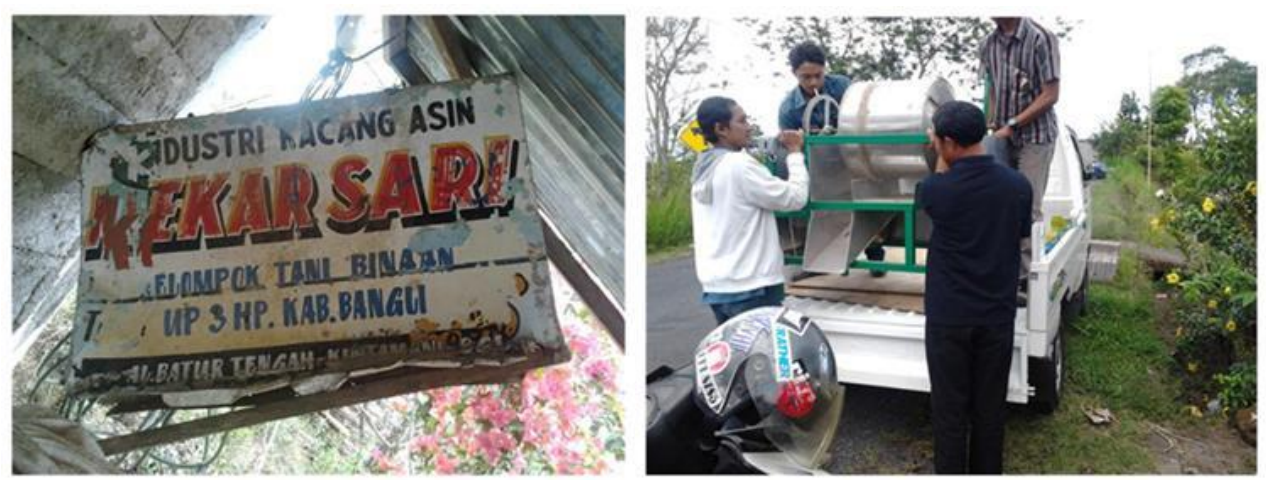

Gambar 3.Mesin sangrai dibawa ke mitra
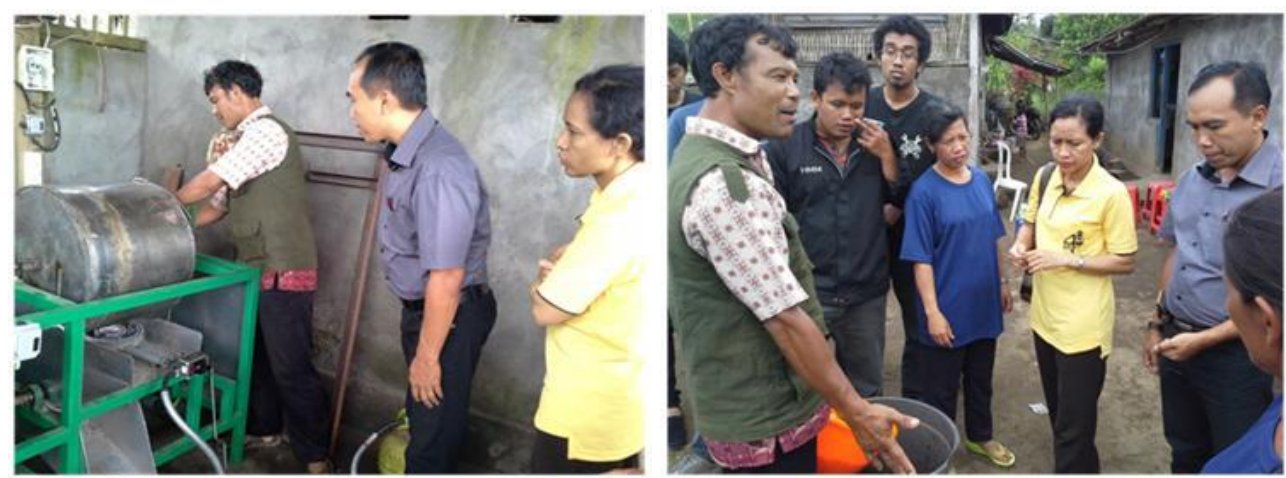

Gambar 4.Kegiatan di mitra

Setelah dilakukan kegiatan pengabdian dapat disimpulkan bahwa kegiatan penyuluhan tentang pentingnya teknologi tepat guna terutama yang berkaitan dengan usaha mereka serta demo dan penyerahan alat hasil rancangan mendapat respon yang baik.

\section{SIMPULAN DAN SARAN}

Simpulan

- Tim telah berhasil merancang dan membuat mesin sangrai kacang asin semi otomatis yang dapat membantu pengusaha kacang asin dalam meningkatkan hasil produksi, dimana dari hasil kegiatan tersebut terdapat peningkatan produksi hampir 5 kali lipat.

- Pelatihan ini dapat meningkatkan ketrampilan tenaga kerja dalam memproduksi kacang asin.

- Melalui pengabdian ini terdapat tukar informasi antara tim sebagai akademisi di kampus dengan masyarakat, aparatur desa/banjar, dan para pengusaha pengusaha kecil di desa dalam meningkatkan potensi mereka.

Saran

- Berdasarkan fakta dilapangan, hendaknya masing-masing anggota memiliki tugas yang pasti karena selama ini pengerjaan dilakukan berdasarkan kehadiran anggota sehingga tugasnya jadi tidak teratur.

- Pelaksanaan Pengabdian Masyarakat mendatang hendaknya perlu terus ditingkatkan, terutama dalam pembiayaan agar dapat benar-benar dapat membuat sesuatu yang baik.

\section{UCAPAN TERIMAKASIH}


Artikel ini disusun dari kegiatan pengabdian yang merupakan hibah Udayana Mengabdi yang didanai dari PNBP Unud tahun 2018. Untuk itu penulis menyampaikan terima kasih yang sebesarbesarnya kepada LPPM Universitas Udayana atas dukungan dana kegiatan pengabdian ini serta mendukung dan memfasilitasi kegiatan pengabdian masyarakat ini.

\section{DAFTAR PUSTAKA}

Juvinall, R. C. (2007). Fundamentals of machine component design.

Mott, R. L. (2009). Elemen-elemen mesin dalam perancangan mekanis. Penerbit ANDI, Yogyakarta.

Mulato, S. (2002). Perancangan dan pengujian mesin sangrai biji kopi tipe silinder. Jurnal Pelita Perkebunan, 18(1), 31-45.

Mulyanto, D. (2006). Usaha kecil dan Persoalannya di Indonesia. Yayasan Obor Indonesia. 